\title{
Effects of gelcoat thickness on mechanical properties of woven glass/polyester laminated composite
}

\author{
M. Y. Yuhazri ${ }^{*}$, M. H. Amirhafizan' ${ }^{2}$, G. C. H. Nilson ${ }^{1}$, H. Sihombing ${ }^{3}$, A. M. \\ Kamarul $^{1}$ and U. Nirmal ${ }^{4}$ \\ ${ }^{1}$ Faculty of Engineering Technology, \\ ${ }^{2}$ Faculty of Manufacturing Engineering, \\ ${ }^{3}$ Faculty of Technology Management and Technopreneurship \\ Universiti Teknikal Malaysia Melaka, \\ Hang Tuah Jaya, 76100, Durian Tunggal, Melaka, Malaysia. \\ *Email: yuhazri@utem.edu.my \\ Phone: +603316895; Fax: +603316411 \\ ${ }^{4}$ Faculty of Engineering and Technology, Multimedia University, \\ Jalan Ayer Keroh Lama, 75450, Melaka, Malaysia.
}

\begin{abstract}
In this study, effects of gelcoat thickness on the mechanical properties and interfacial bonding of woven glass/polyester laminated composite are investigated by using threepoint flexural test and tensile test. The composites had been applied at variance thickness of gelcoat layers $(0.25,0.3,0.35,0.4,0.45$, and $0.5 \mathrm{~mm})$ using hand lay-up method. Samples were measured in two techniques for the flexural test, i.e., coated surface facing the loads (concave) and bare surface facing the loads (convex). Since the coated surface was concavely bent, greatest increase of flexural strength that acquired 5fold of increase was shown by composite with $0.3 \mathrm{~mm}$ of gelcoat thickness for both measurements. The increasing of thickness to $0.35 \mathrm{~mm}$ and above deflated the rising percentage in flexural strength. This event was happened because of the gelcoat thickness ratio was greater than the matrix/reinforcement ratio. For tensile test, composite applied with gelcoat of $0.4 \mathrm{~mm}$ thickness exhibited the highest increase in strength. An increase of almost $38 \%$ in tensile strength was recorded compared to the uncoated composite. Similarly, the increase in tensile strength reduced slightly when the gelcoat thickness was increased above $0.4 \mathrm{~mm}$. The results demonstrate that the mechanical properties of the composite improve as the gelcoat thickness increases. However, the mechanical properties show no further improvement as the thickness is further increased above the optimum thickness.
\end{abstract}

Keywords: Gelcoat; thickness, fracture, laminated, composite

\section{INTRODUCTION}

Gelcoat is a material used applied to molds in the liquid state to provide a high-quality finish on the visible surface of a fiber-reinforced composite material. Naturally the gelcoat is applied at the outermost surface of the product as protection from contamination or harsh environment. As a result, the gelcoat facing top as the most ideal result because as usual the external force are is applied from outside. For example, gelcoat usually use on the boat manufacturing industry which were gel-coated on the 
ship or yacht body. The main purpose of gelcoat is to protect the entire ship body from the chemical attack of the salt water and prevention impact from the hard object [1].

Mostly gelcoats are formed on epoxy or unsaturated polyester resin. Crosslinked polymers are built by cured gelcoats and latterly approved with polyester resin and fiberglass or epoxy resin with glass mixtures which are the composite polymer matrices. One of the methods to enhance the composite performance is by improving the gelcoat properties. See et al. [2] demonstrated that by adding modified montmorillonite (MMT) nanoclay into gelcoat, moisture diffusivity was progressively reduced while maintaining its physical integrity. Karapappas et al. [3] studied the effect of nanofillers in epoxy gelcoat. They found that conductive fillers showed an increase in tensile and fracture properties, as well as in the thermal properties whereas the non-conductive fillers did not show any improvement on the fracture properties.

Chemical reaction that occurs at the first layer of the laminate which is applied to gelcoat layer that has not completely cured was specified by Sockalingam and Nilakantan [4]. The two layers were eventually cured together by a chemical bond between them. Excessive catalyst resulting in produced the brittle gelcoat layer which evokes it to shiver with a bit stimulus [5]. The flexible gelcoats that still not affected to shivering, deviated toward immature colour worsening, gloss deficit, chalking or chemical attack. Assorted and uniformly diffused filler in the liquid resin guaranteed consistent flame retardant properties throughout the polymer showed by Mouritz [6] and Pomázi [7]. Mostly polymers need an excessive stacking of filler to display an observable progression to their flammability resistance. The fillers have different deleterious effects on the properties, including an increase to the viscosity and reduction of gel time for the polymer melt which makes processing more difficult.

Capela et al. [8] revealed that the fatigue and impact loading achievement of glass mat/polyester composite had been influenced by gelcoat surface layer. It was shown that the composites coated with gelcoat layer and tested under compression loading exhibited critical higher bending stiffness, static and fatigue strength. The impact response set out a minor variation of the peak load and the elastic recuperation where a substantial increased on maximum displacement and absorbed energy with the inclining of incident impact energy. McCrary-Dennis and Okoli [9] added the mechanical performance of the composite crucially resolved by the interface and interphase between the gelcoat and laminate composite. Ultimately, the quality of interface defined the impressive advancement of a composite material. The reintroduction of stress is manipulated by interface into either component at a damage site.

Previous studies mainly concentrate on the performance of gelcoat as the protective layer for laminate composite through adjusting the mixing ratio of catalyst and resin to control the curing of gelcoat. Through comprehensive literature review shows that there are no scientific studies reported on gelcoat thickness affected to composite performance, therefore, another motivation for this study is to understand the effect of gelcoat on the laminate structure. In this study effects of gelcoat thickness on the flexural and tensile properties of glass/polyester laminated composite are investigated as an approach to estimate the optimum gelcoat thickness for the composite.

\section{METHODS AND MATERIALS}

The gelcoat used in this study was polycor GP-Has were supplied by Cray Valley Resins (M) Sdn. Bhd with properties as shown in Table 1. Polyester resin (Norsodyne $3110 \mathrm{~W}$ ) for the matrix was purchased from CCP Composites Corp. The catalyst used 
was $1 \%$ of MEKP for both the gelcoat and matrix preparation to ensure proper curing in room temperature. As for the reinforcement, 4-plies of glass fibers with diameter of $300 \times 300(w \times l) \mathrm{mm}$ were used (the size before cut into specific specimen size) and the matrix material (polyester) always fixed at $60 \mathrm{wt} . \%$ according to rule of mixer.

Table 1. Technical data of polycor GP-H gelcoat [10].

\begin{tabular}{ll}
\hline Viscosity & $16,000-22,000$ \\
Thixotropic Index & $6.0-8.0$ \\
Volatile Organic Compound & $38.7-40.7 \%$ \\
Flash Point & $82 \mathrm{~F}$ \\
Geltime With 1.8\% MEKP & $10.0-15.0 \mathrm{mins}$ \\
Lay-up Time & $45-60$ mins \\
Sag Resistance & Good @ 20 mils wet \\
\hline
\end{tabular}

Gelcoat layers were applied on the glass/polyester composites by using hand lay-up method as illustrated in Figure 1(a). The gelcoat was applied using brush on the surface of plastic film after cleaning process to prevent any contamination. Each coated layer was measured by using wet film thickness gauge as shown in Figure 1(b), to ensure the gelcoat was spread evenly on the surface and left for 10 minutes to cure. The steps were repeated until the desired gelcoat thickness was acquired. In order to prevent the external force or pressure from being applied to the gelcoat layer, each ply of glass fiber was wetted with resin before being placed on the gelcoat. The samples were then wrapped according to standard sequence of vacuum bagging technique using peel ply, perforated film, breather, mesh flow and lastly covered by bagging plastic. The laminated composites were left for 24 hours to let them cure completely.

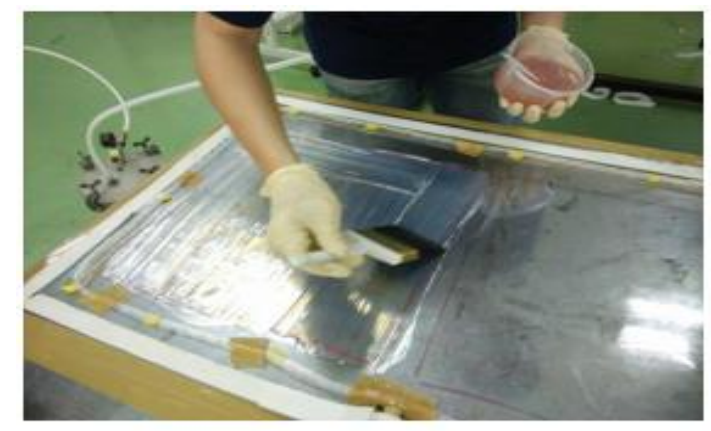

(a)

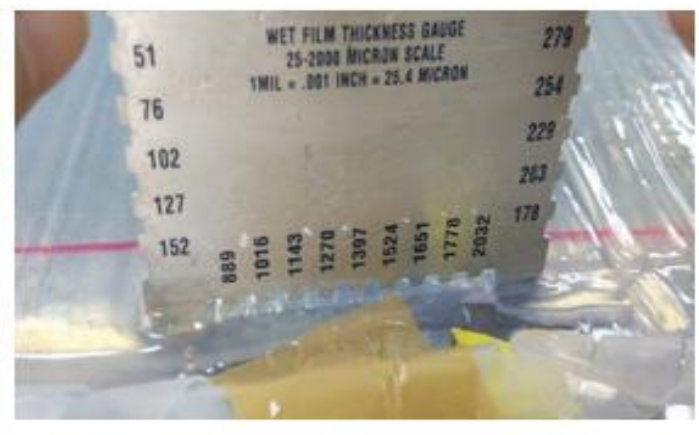

(b)

Figure 1. (a) Gelcoat application using brush, and (b) thickness measurement.

Tensile test was conducted in accordance to ASTM D3039-00 standards. The specimens were analysed at a speed rate of $2 \mathrm{~mm}$ per minute. The stress strain curve resolved the interfacial bonding strength of various gelcoat thickness. Figure 2 showed the same machine (Shimadzu Universal Testing Machine) as agreeing in ASTM D790-02 was used to perform the flexural test in two ways, i.e., coated surface facing the load (concave) and bare surface facing the load (convex) to measure the samples. The objective was to record the failure behaviour of gelcoat on both concave and convex face. Each gelcoat thickness was tested with 8 samples and the average value was listed. The maximum compressive strain value of stress was found at concave side while maximum tensile value was found at convex side. Six different thickness of gelcoat 
were used in total, i.e., $0.25,0.30,0.35,0.4,0.45$ and $0.50 \mathrm{~mm}$. Figure 3 showed the cross-sectional image of the coated laminated composite.

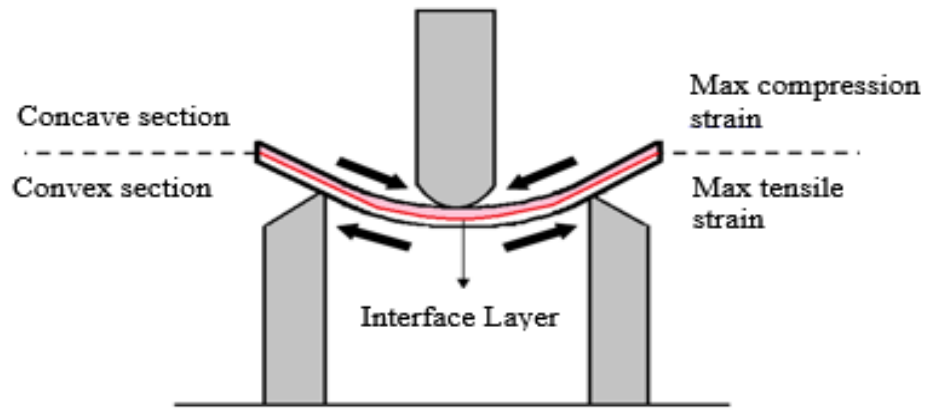

Figure 2. Concave and convex face under three point flexural test.

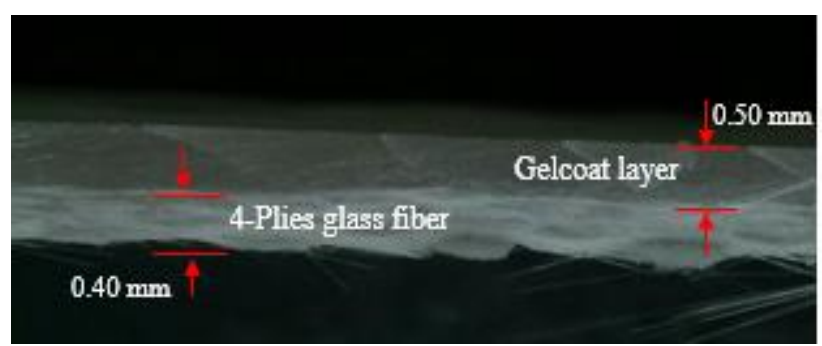

Figure 3. A cross-sectional image of the coated composite.

\section{RESULTS AND DISCUSSION}

\section{Three Point Flexural - Concave Performance}

Table 2 shows the deflection and failure behavior of glass/polyester composite coated with different thickness of gelcoat under flexural loading with the gelcoat side is concavely bent. The gelcoat thickness of $0.25 \mathrm{~mm}$ that was concavely bent showed the gelcoat fractured at the compression point between the crosshead and the specimen. However, the fractured pieces did not stick to the laminates but drop off from the specimen. When the gelcoat thickness is increased to $0.30 \mathrm{~mm}$, a different crack pattern is observed. The crack is observed at a position few millimeters from crosshead bar, instead of directly below it. This is probably due to the specimen not transferring the load applied equally along the surface of gelcoat and the specimen started to crack at the defect of the gelcoat which located at the edge of specimen [10]. The specimen shows flexibility to recover back but not exactly to its original shape with little bent condition. Composites coated with gelcoat thickness of $0.35 \mathrm{~mm}$ and $0.40 \mathrm{~mm}$ show a similar cracking behavior which exhibit smooth gelcoat surface but contain few internal cracks. Most of the internal cracks occur directly parallel to the crosshead bar but do not reach the surface of the gelcoat.

However, when the gelcoat thickness is increased to $0.45 \mathrm{~mm}$ and $0.50 \mathrm{~mm}$, cracks are spotted at the edge of the specimen where the interface between the gelcoat and laminates is located. The gelcoat surface for $0.45 \mathrm{~mm}$ maintains as clean and smooth surface but not in the $0.50 \mathrm{~mm}$, where obvious surface cracks are observed. As in concave bending, the gelcoat surface faces the maximum compression load but the middle of the specimen acts a neutral axis. Since the laminates of different gelcoat are the same, the maximum tensile value sustain by the laminates are the same after the gelcoat is completely fail. 
Table 2. Deflection and failure behavior of gelcoat under concave bending.

\begin{tabular}{|c|c|}
\hline Thick & $\begin{array}{l}\text { - Crack Pattern: Crack starts from the direct } \\
\text { contact point between the crosshead bar and } \\
\text { gelcoat surface. } \\
\text { - Scenario: Some of the gelcoat fragments are } \\
\text { detached from the specimen during the test. } \\
\text { Obvious gelcoat cracking can be observed. }\end{array}$ \\
\hline Thickness $=0.30 \mathrm{~m}$ & $\begin{array}{l}\text { - Crack Pattern: Gelcoat crack occurs not } \\
\text { directly under crossbar but few millimeters from } \\
\text { it. } \\
\text { - Scenario: The gelcoat cracks stick along with } \\
\text { the laminates. }\end{array}$ \\
\hline Thickness $=0.3$ & $\begin{array}{l}\text { - Crack Pattern: Few internal cracks that } \\
\text { propagate horizontally across the specimen are } \\
\text { observed in the gelcoat. } \\
\text { - Scenario: The gelcoat surface is smooth and } \\
\text { without any obvious surface crack. }\end{array}$ \\
\hline & $\begin{array}{l}\text { - Crack Pattern: Few internal cracks that } \\
\text { propagate horizontally across the specimen are } \\
\text { observed in the gelcoat. } \\
\text { - Scenario: The gelcoat surface is smooth and } \\
\text { without any obvious surface crack. }\end{array}$ \\
\hline & $\begin{array}{l}\text { - Crack pattern: The gelcoat surface is smooth } \\
\text { but serious internal crack and spacing appears at } \\
\text { the middle of specimen. } \\
\text { - Scenario: The specimen is unable to recover } \\
\text { back to its original shape. }\end{array}$ \\
\hline & $\begin{array}{l}\text { - Crack pattern: Obvious gelcoat surface cracks } \\
\text { with spacing in between and direct link to } \\
\text { internal cracks are observed. } \\
\text { - Scenario: Some tiny cracks occur at the edge of } \\
\text { the specimen but do not propagate across the } \\
\text { specimen. }\end{array}$ \\
\hline
\end{tabular}


Most of the cracks start at the crosshead pointing area and propagate through the crosssection of the gelcoat. Some of the tiny cracks start at the edge of the gelcoat. Ennos and Casteren [11] mentioned that the concave side should yield in longitudinal compression, it will not actually break and tensile failure will then occur on the convex surface. The fracture should be diverted along the branch half way through because of its low tangential tensile strength.

Failure analysis is very important in the design procedure to assure the material properties by combining tests [12]. In order to determine the failure pattern of the samples, one sample was selected from the highest and lowest thickness to be analyzed using scanning electron microscope (SEM). The purpose is to elucidate the crack pattern at the failure point. As shown in the SEM image in Figure 4, there is an obvious breakage between the laminates that caused by the compression of the crosshead bar in the composite coated with $0.25 \mathrm{~mm}$ thick gelcoat. This indicates the interface bonding between gelcoat and laminate is well bonded in $0.25 \mathrm{~mm}$ that although the laminate has failed but the interface bonding is still maintained. Defect like voids are also observed to appear between the gelcoat and laminate that may cause the weakening of the mechanical strength. Knoeller and Rome [13] stated that a reduction of nearly $7 \%$ for every $1 \%$ of voids present was experienced by the interlaminar strength, up to a void content of $4 \%$. Moreover, for each $1 \%$ incline in voids, the fatigue life of fiberreinforced polymer matrix composites was weakened by $5 \%$ and the strength by approximately $5 \%$. This degradation in strength properties lead polymer matrix composites to be more exposed to reduction in aggressive environments.

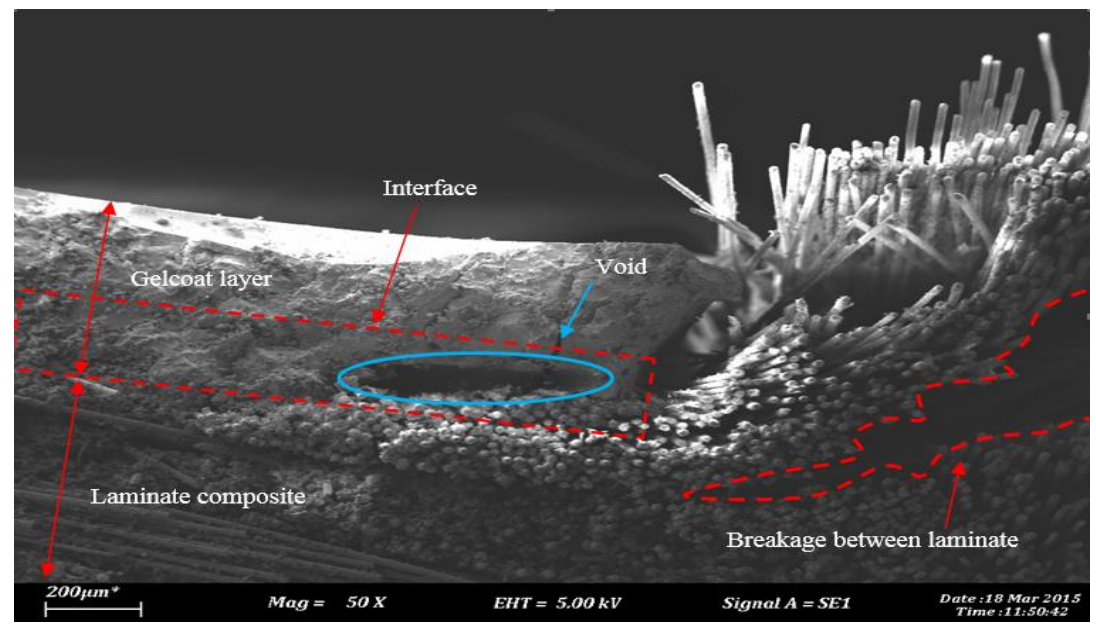

Figure 4. Failure found in the sample with $0.25 \mathrm{~mm}$ gelcoat thickness.

The image of $0.5 \mathrm{~mm}$ gelcoat thickness sample under flexural loading is shown in Figure 5. It is certainly discovered that a crack occurs in the middle of the compression point and generates an obvious surface crack and spread till the interface until the total fracture take place. The appearance of slight voids close to the interface between the gelcoat and laminates is shown in the cross-section of the sample with $0.50 \mathrm{~mm}$ gelcoat thickness in Figure 6. This explained the interface cracking in Figure 4. The mechanical strength is declined because the cracking spread through the tiny void and unable to bear the compression load. 


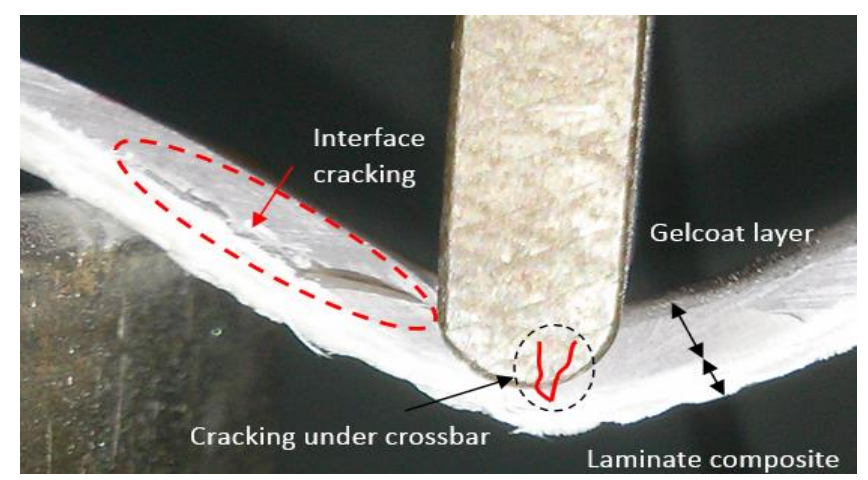

Figure 5. Fracture occur at sample of $0.50 \mathrm{~mm}$ gelcoat thickness.

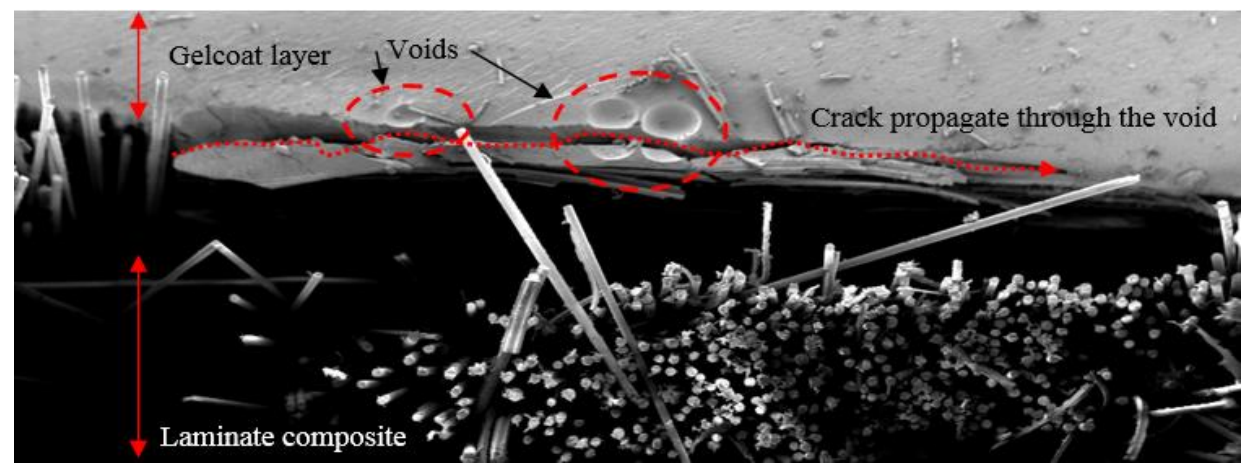

Figure 6. Tiny voids found at the interface between gelcoat layer and laminates.

\section{Three Point Flexural - Convex Performance}

Table 3 shows the deflection and failure behavior of glass/polyester composite coated with different thickness of gelcoat under flexural loading with the gelcoat side is convexly bent. Composite coated with $0.25 \mathrm{~mm}$ of gelcoat thickness that was bent convexly showed a break directly under the compression point. The failure pattern of the gelcoat is a clean breakage which is straight and different to the gelcoat bent concavely that shows multiple cracks on the break point. There are few tiny cracks appear on the crack point of the gelcoat which combine as they propagate. In the composite coated with $0.30 \mathrm{~mm}$ gelcoat, the crack begins next to the compression point. For the gelcoat thickness of $0.35 \mathrm{~mm}$ and $0.40 \mathrm{~mm}$, they experience the same failure condition with cracks start at the middle point of the specimen and propagate till opposite edge side with branch cracking pattern. Although there are small tiny crack occur at the edge in the same time, but once a crack have linking with the internal crack propagation, the crack turns into failure in a second.

Composites coated with $0.45 \mathrm{~mm}$ and $0.50 \mathrm{~mm}$ gelcoat show different crack propagation pattern under convex bending. The gelcoat thickness of $0.45 \mathrm{~mm}$ shows the teeth pattern crack propagation, while $0.50 \mathrm{~mm}$ gelcoat shows a crack pattern that starts from many tiny cracking that propagate to one single point. The gelcoat crack point continues to expand along the crosshead compression point continuously. The glass fiber break is not that obvious in the convex bending compares to the concaves bending. Baghaei et al. [14] stated that failure will occur when the weakest fiber hit its limiting tensile stress because of all the fibers in the composite under the same stress since identical specimen is subjected to tensile forces. 
Table 3. Deflection and failure behavior of gelcoat under convex bending.

\begin{tabular}{|c|c|}
\hline Thickness $=0.25 \mathrm{~mm}$ & $\begin{array}{l}\text { - Crack Pattern: Many tiny cracks are observed } \\
\text { around the failure edge. } \\
\text { - Scenario: Horizontal crack occurs at the } \\
\text { gelcoat surface directly under the crosshead } \\
\text { bar. }\end{array}$ \\
\hline ess $=0.3$ & $\begin{array}{l}\text { - Crack Pattern: A clean horizontal crack along } \\
\text { the sample. } \\
\text { - Scenario: Gelcoat crack occurs not directly } \\
\text { under the crosshead bar but few millimeters } \\
\text { next to the crack point. }\end{array}$ \\
\hline Thickness $=0$. & $\begin{array}{l}\text { - Crack Pattern: Branched crack starting at one } \\
\text { point and spread across the specimen. } \\
\text { - Scenario: The gelcoat crack starts at the edge } \\
\text { of the specimen and propagates throughout the } \\
\text { specimen. }\end{array}$ \\
\hline Thicknes: & $\begin{array}{l}\text { - Crack Pattern: Two edge cracks occur but } \\
\text { only one crack propagates and forms a } \\
\text { branched crack. } \\
\text { - Scenario: There are more than one gelcoat } \\
\text { crack started at the edge of the specimen but } \\
\text { only one point propagates separately through } \\
\text { the specimen while the other stops propagating. }\end{array}$ \\
\hline & $\begin{array}{l}\text { - Crack Pattern: Inconsistent teeth crack pattern } \\
\text { is observed at the crack edge. } \\
\text { - Scenario: A fast gelcoat failure occurs and } \\
\text { causes direct drop of the maximum stress value. } \\
\text { The crack edge shows inconsistent teeth } \\
\text { structure. }\end{array}$ \\
\hline Thicknes & $\begin{array}{l}\text { - Crack Pattern: Less branched crack occurs but } \\
\text { higher spacing observed between the cracks } \\
\text { formed. } \\
\text { Scenario: A sudden fracture occurs and } \\
\text { propagates across the specimen. The crack } \\
\text { point expending directly under the crosshead } \\
\text { bar while other crack next to it remains } \\
\text { unchanged. }\end{array}$ \\
\hline
\end{tabular}


The tensile fracture exists on the convex side and able to spread throughout the specimen to completely fall apart. The cracks widen closely to the mid-point of the specimen where it then diverts into the longitudinal direction when the thickness of gelcoat is in its highest state.

From overall observation of the cracking of composites coated with different gelcoat thickness under convex bending, they mostly show branch cracking pattern. At first, the compression load is inclined thus the edge of the sample start cracking but only one crack continuosly spread across the sample until the interlace between the gelcoat and laminates when higher compression is assigned. Orifici [15] defined that concepts in different loading scenarios and laminate configurations is controlled by the capability of crack and the crack branching mechanisms. The crack patterns that showed up in the gelcoat is shown in Figure 7 (a) and (c).
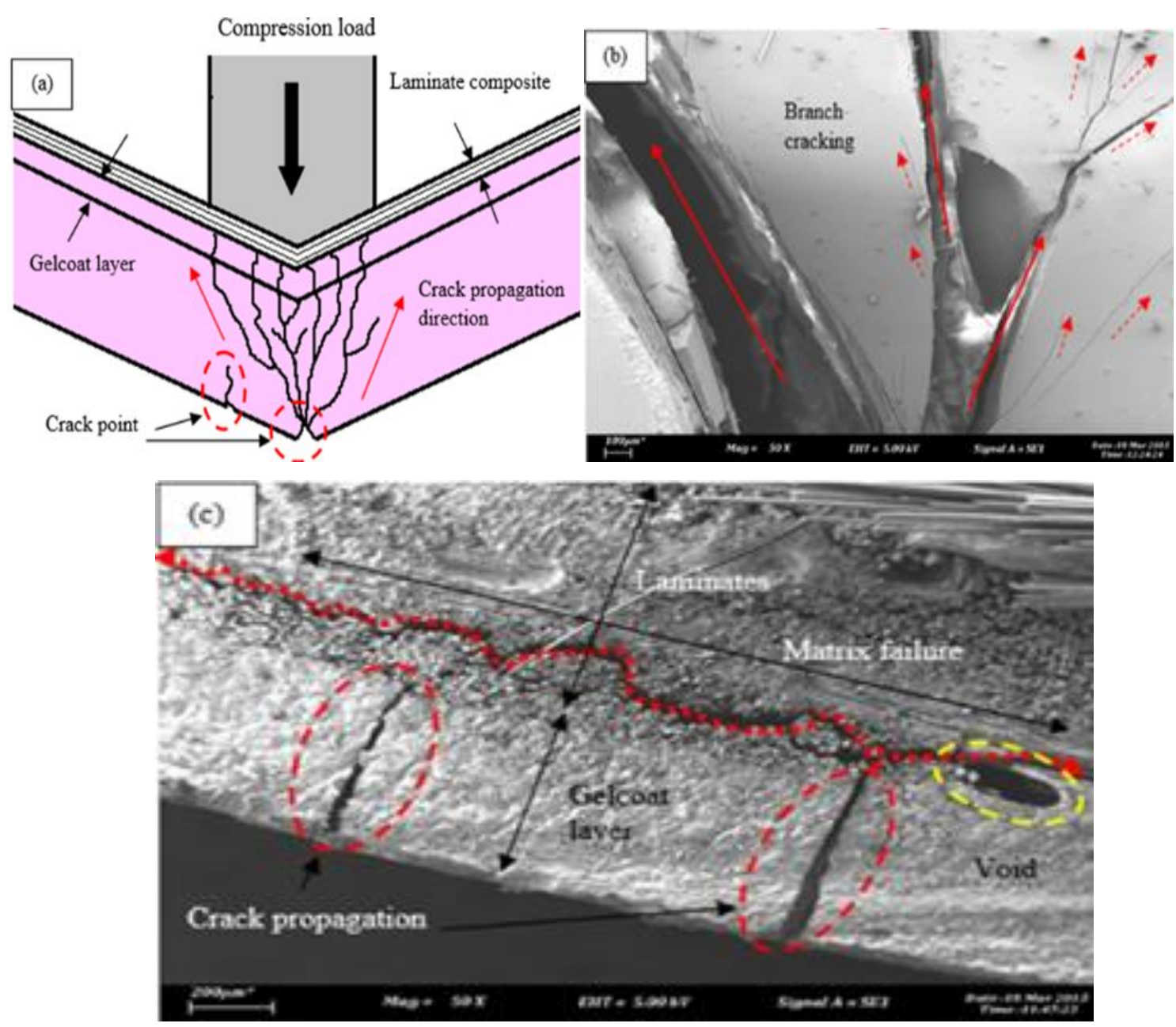

Figure 7. (a) Crack pattern in the gelcoat layer; (b) Branch cracking at gelcoat surface;

(c) Matrix failure of laminates

The SEM image of crack propagation in the coated laminated composite is shown in Figure 7 (c). The crack only spread through the laminate not the interface section, keep the gelcoat well bonded. Hence it can be verified that a failure between the plies is matrix failure. The study of Maksimović [16] stated that four basic modes of failure that occur in laminate composite structures are: matrix cracking, fiber-matrix shear failure, 
fiber failure and delamination. Khelifa and Al-Shukri [17] argued that failure of laminas at $\pm 45^{\circ}$ and $0^{\circ} / 90^{\circ}$ is due to matrix failure in the direction of the fiber, whereas for the unidirectional lamina at $0^{\circ}$, the failure is due to fiber breakages. The fiber damage begins to occur once the number of fatigue cycles reaches sufficient numbers and combined matrix and fiber damages predominate, giving rise to the rapid weakening of the composites.

The purpose of the matrix in a fiber reinforced composite is to move the load to the stiff fibers through shear stresses at the interface [18]. A proper bond between the polymeric matrix and the fibers is required in this process. The composite life span is at risk to be reduced due to the poor adhesion at the interface that cause the capabilities of the composite unable to be fully exploited and leave it defenceless to environmental attacks. From the fractured surface of flexural test samples, the SEM analysis on the crosssection showed that the failures of specimens were mostly characterized by crack propagation of gelcoat surface till the internal layer of the laminates but not through the interface. Although the higher gelcoat thickness showed failure at the interface, it was the due to voids present in the interface section that caused the weakening of mechanical strength as the gelcoat surface crack propagates till the internal layer and passed through the void as shown in Figure 8(a). Figure 8(b) shows the failure of the matrix at the four plies laminates. There are delamination in the matrix that link together and cause the debonding of the in between the fiber layers. It can define that interface bonding in between the gelcoat layer and laminates are well mechanical bonded either on the low and high gelcoat thickness. The SEM images show that the delamination usually occurs at between plies as compared to the interface.

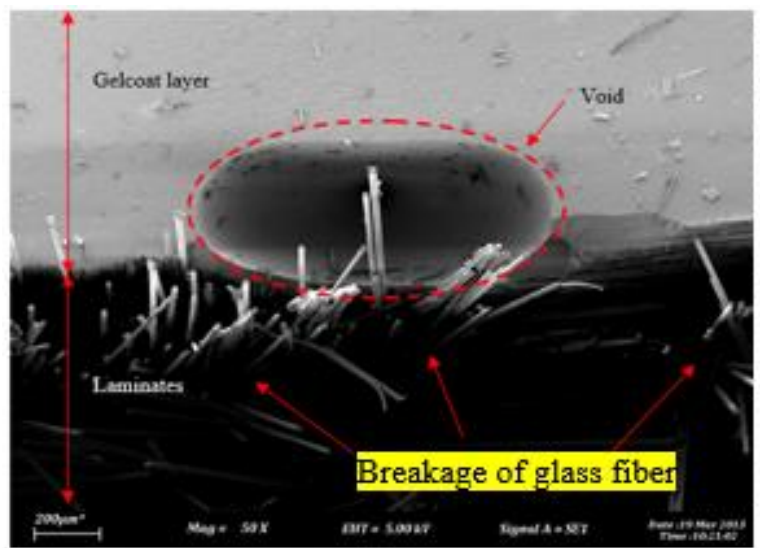

(a)

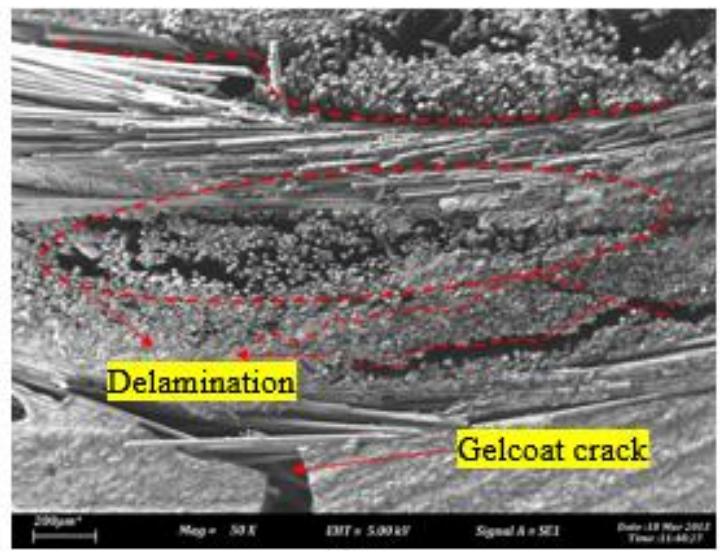

(b)

Figure 8. (a) Void discovered at the interface between gelcoat and laminates; (b) Delamination observed at the 4-plies laminate.

\section{Three Point Flexural - Maximum Stress Sustained}

Based on Table 4, the result of flexural test prove that the maximum flexural does not given by the composite with greatest gelcoat thickness. The uncoated glass/polyester laminates composite only can keep up to $69.80 \mathrm{~N} / \mathrm{mm}^{2}$ stress. The flexural strength inclined excellently to about $395.95 \mathrm{~N} / \mathrm{mm}^{2}$ when measured with the $0.25 \mathrm{~mm}$ gelcoat facing up, which is more than 5-fold of increase. However, the flexural strength is a little bit low which is at $208.89 \mathrm{~N} / \mathrm{mm}$ when the gelcoat is bent convexly (facing down). This proved that the flexural strength can be improved by the application of gelcoat significantly. The progression in mechanical properties can be affected by gelcoat 
application, which make material operable in high-loading environment, reviewed by Jawahar et al. [19].

Table 4. Average maximum flexural stress of both glass/polyester composite coated with gelcoat of various thickness.

\begin{tabular}{ccccc}
\hline $\begin{array}{c}\text { Gelcoat } \\
\text { Thickness } \\
(\mathrm{mm})\end{array}$ & $\begin{array}{c}\text { Gelcoat Bottom } \\
\text { Average Max } \\
\text { Stress }\left(\mathrm{N} / \mathrm{mm}^{2}\right)\end{array}$ & $\begin{array}{c}\text { Percentage } \\
\text { of increase } \\
(\%)\end{array}$ & $\begin{array}{c}\text { Gelcoat Top } \\
\text { Average Max } \\
\text { Stress }\left(\mathrm{N} / \mathrm{mm}^{2}\right)\end{array}$ & $\begin{array}{c}\text { Percentage of } \\
\text { increase } \\
(\%)\end{array}$ \\
\hline 0.00 & 69.80 & - & 69.80 & - \\
0.25 & 208.89 & 194.90 & 395.95 & 467.30 \\
0.30 & 245.16 & 251.20 & 517.28 & 641.10 \\
0.35 & 134.66 & 92.90 & 242.59 & 247.60 \\
0.40 & 98.19 & 40.70 & 235.92 & 237.90 \\
0.45 & 111.47 & 59.70 & 306.02 & 338.40 \\
0.50 & 125.31 & 79.50 & 343.52 & 392.20 \\
\hline
\end{tabular}

However, the percentage of increase in flexural strength slightly reduces when the thickness is further increased to $0.35 \mathrm{~mm}$. Moreover, sample with gelcoat thickness of $0.40 \mathrm{~mm}$ showed the lowest value among the coated sample at 98.19 and $235.92 \mathrm{~N} / \mathrm{mm}^{2}$ for the gelcoat facing down and up, respectively. Figure 10 shows the maximum stress obtained in the flexural tests of the composites for both measurement methods. In general, higher flexural strength is achieved when the gelcoat is facing up. Flexural strength increases again when the thickness is further increase from $0.40 \mathrm{~mm}$, but the increase is small and causes an increase in material cost.

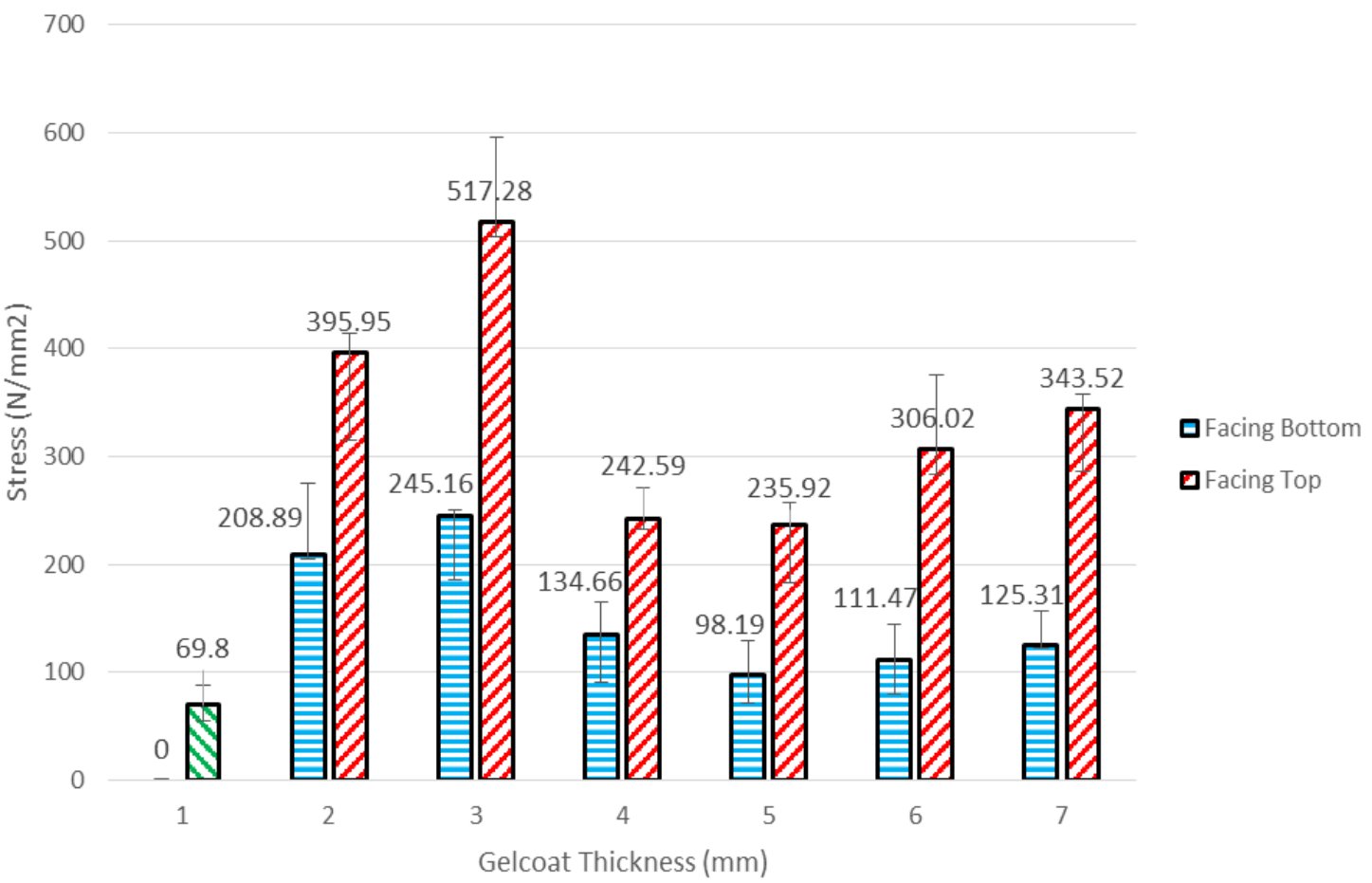

Figure 9. Flexural strength of glass/polyester composite convexly (left bars) and concavely (right bars). 
As shown in Figure 9, despite having the highest thickness of gelcoat, samples with 0.5 $\mathrm{mm}$ of gelcoat do not give the highest strength. The optimum thickness found in this study is slightly lower than that suggested in the Crystic Polyester Handbook [20], which states that the gelcoat thickness should be in the range $0.4 \mathrm{~mm}$ to $0.5 \mathrm{~mm}$ for most applications, or $0.5 \mathrm{~mm}$ till $0.6 \mathrm{~mm}$ thick for mold tools. At a thickness below 0.4 $\mathrm{mm}$, there may be incomplete cure, reinforcement print-through and an increased probability of osmosis leading to blistering. Based on the result obtained, we suggest that when the gelcoat thickness is further inclined, it is not necessarily for the mechanical properties to improve and there is a certain optimum value for gelcoat thickness. Moreover, the gelcoat surface will be brittle at greater thickness and extra cost is not equitable as stated by other research [21 -22].

\section{Three Point Flexural - Brittleness of Gelcoat}

Two graphs of $0.25 \mathrm{~mm}$ thickness are selected to show the different steps of failure that occur in flexural test. Figure 10 (a) and Figure 10 (b) show the force-displacement curves for gelcoat bent in convex and concave, respectively. The force required for the gelcoat to fail is larger in sample with facing top (concave bending) than that facing down (convex bending). The same can be said regarding the displacement. This is because when the load transfers between plies, stress transverses to the fiber orientation also are induced in each ply before the load is finally affect the gelcoat to start cracking as suggested by Adams [23]. On the other hand, where the gelcoat is facing top position, the stress received in compressive mode. As brittle materials in general are able to sustain higher compressive stress than tensile one, this explains the larger force needed before the sample to fail when the gelcoat is bent concavely. The fracture of the gelcoat layer is more brittle and shows crack before the glass reinforced plastic as demonstrated in other study [24]. Besides, polycor is a polyester based gelcoat that becomes brittle when shock loading is applied as shown Ahmad and Izhar [25].

(a)

Gelcoat Failure

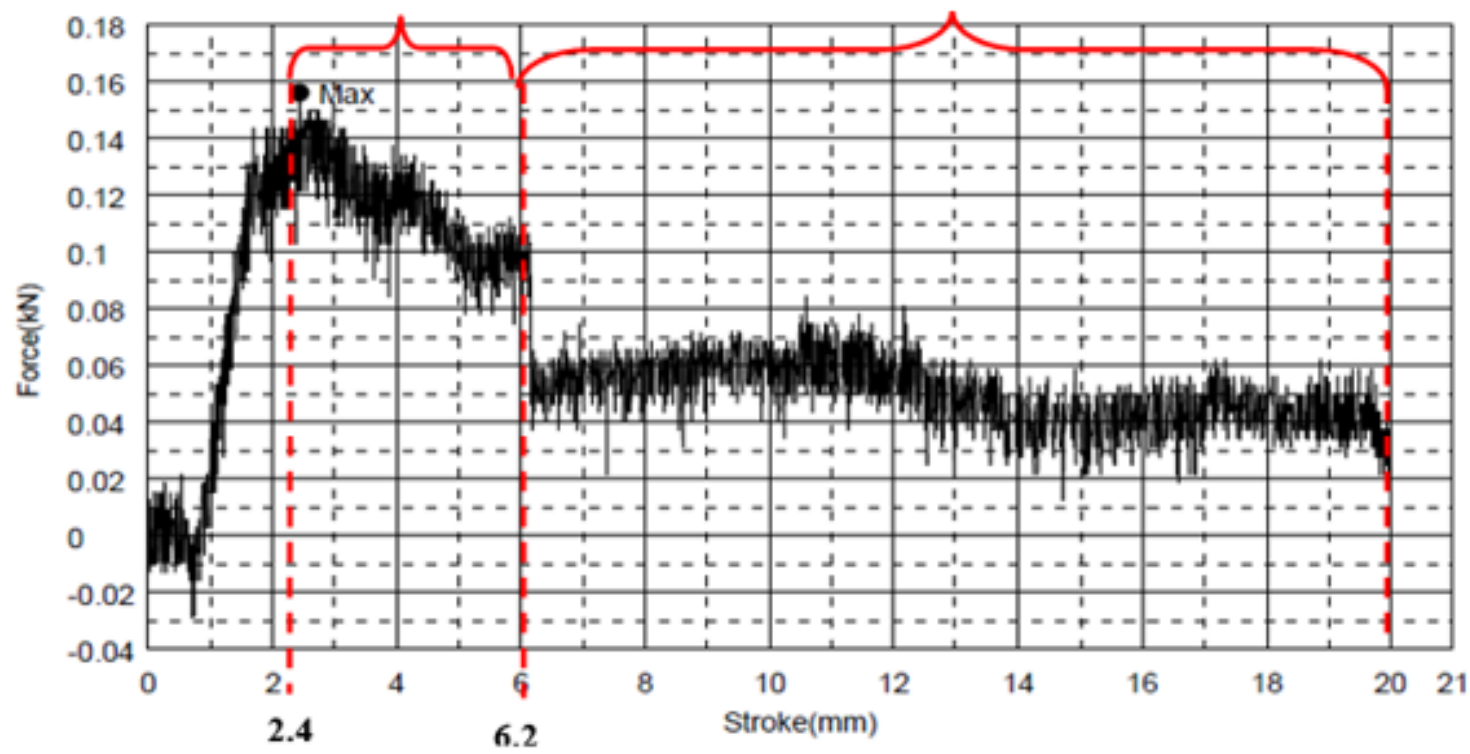




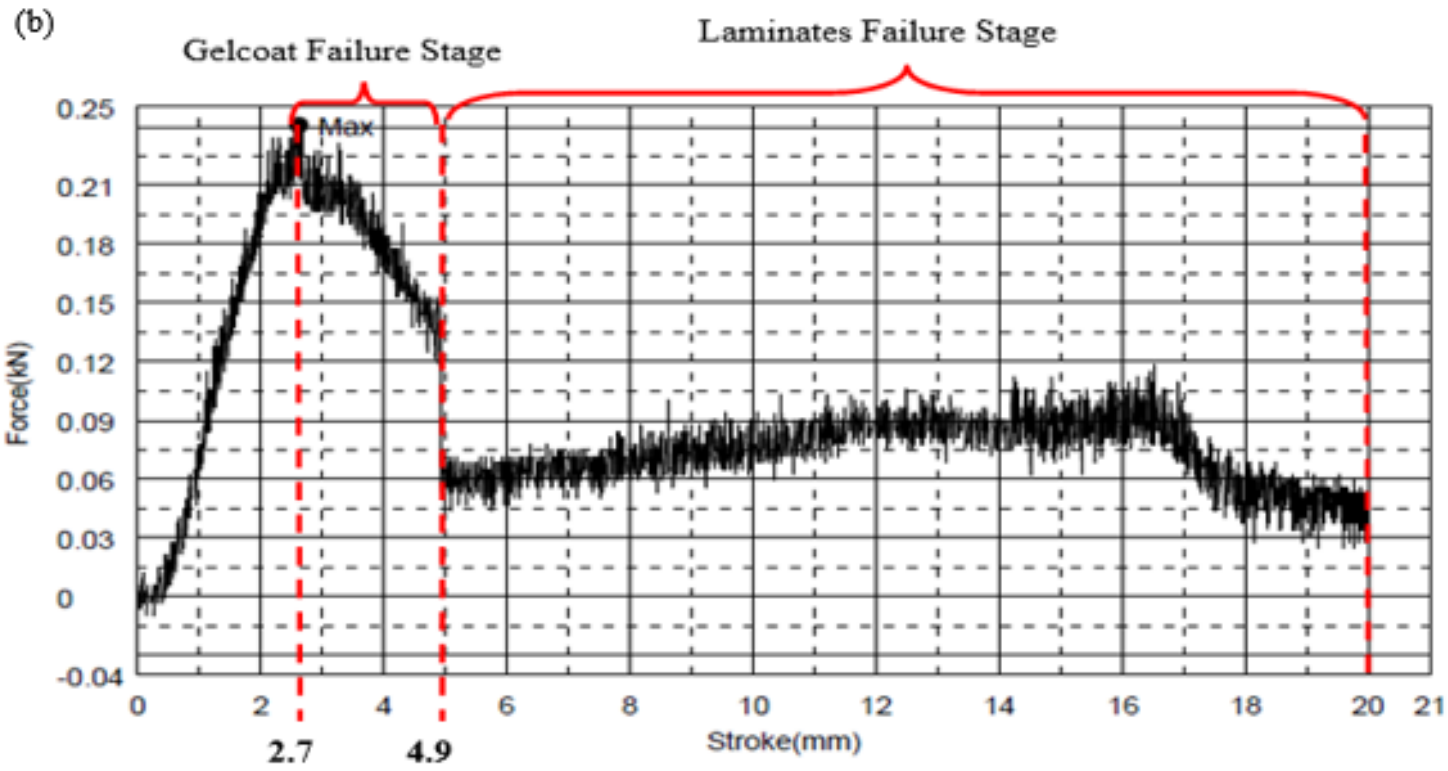

Figure 10. Graph by position of gelcoat facing (a) bottom; (b) top.

The average thickness of gel coat on a part may not prevent cracking. If a part average is $0.45 \mathrm{~mm}$ thick, but the corner area is $0.66 \mathrm{~mm}$, localized cracking may occur in the overthick area. It is important to achieve the proper thickness in the most highly stressed areas of a part. Over thick of gelcoat to an application can lead to a brittle gel coat that cracks with little provocation is proved by Lacovara [5]. Preview on the past statement and research, a proper gelcoat thickness is necessary to be considered in aspect of load sustainability by referring to over thickness of gelcoat will lead to the sudden failure because of brittleness.

As shown in Figure 11, chevron marking can be observed in the cross section of gelcoat layer. The chevron marking are facing toward the fracture point and is a good evidence to show the crack propagation region exhibits brittle fracture emanating from the crack origin. By referring to Kumara et al. [26], composites displaying good interfacial bonding characteristics exhibit brittle fracture. The presence of chevron lines is helpful in identifying the failure origin and the crack propagation directions.

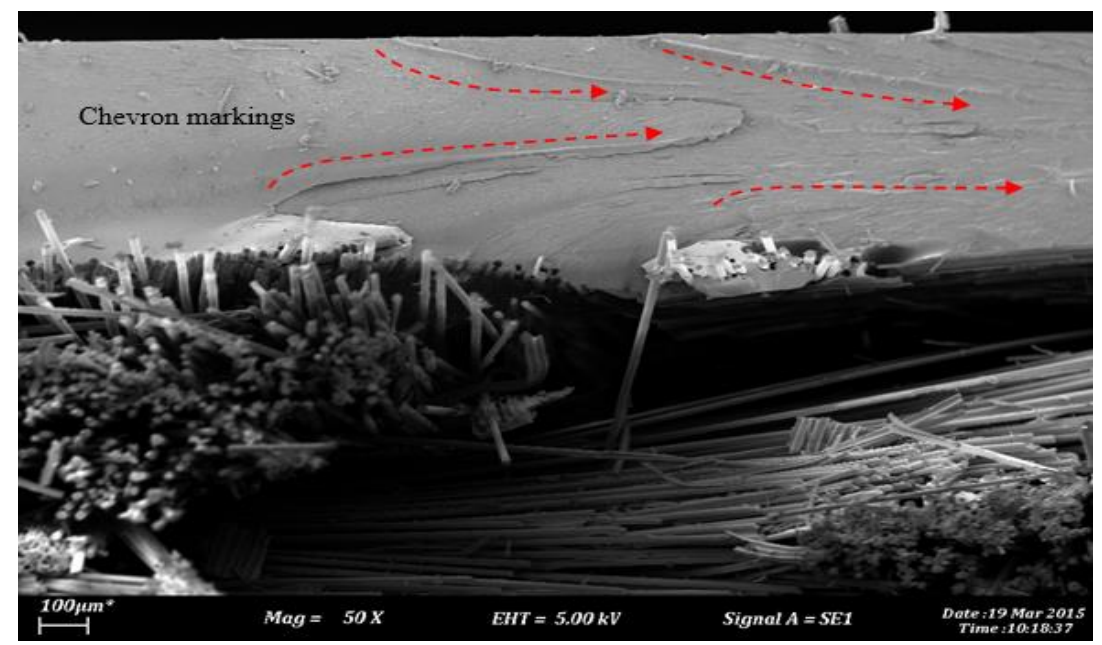

Figure 11. Chevron marking of the gelcoat layer. 


\section{Tensile Properties}

The average maximum force provided by glass/polyester composite coated with gelcoat of different thickness is shown in Figure 12. Meanwhile in Table 5, the percentage of incline in the maximum force before failure in the same system is shown. Based on the table, lowest tensile strength is shown by the uncoated laminated composite. When 0.25 $\mathrm{mm}$ thick gelcoat is applied, the tensile strength value is inclined by $3.15 \%$. The value is continuously inclined when $0.30,0.35$, and $0.40 \mathrm{~mm}$ thick gelcoat are applied significantly. When compared with uncoated composite, the composite coated with 0.4 $\mathrm{mm}$ thick gelcoat experienced $38 \%$ of increase in tensile strength. However, when the thickness is increased to 0.45 and $0.5 \mathrm{~mm}$, there is none dramatic increase have been recorded. The value of maximum force at failure declined almost $20 \%$ when the gelcoat thickness is increased from $0.4 \mathrm{~mm}$ to $0.5 \mathrm{~mm}$. This happened because of increase in brittleness since the gelcoat and the resin-rich surface layer are very brittle and can consequently be ruined when overburdened [27].

Table 5. Average pulling force sustain by different gelcoat thickness sample.

\begin{tabular}{ccc}
\hline Gelcoat Thickness $(\mathrm{mm})$ & Max Force $(\mathrm{N})$ & Percentage of increase (\%) \\
\hline 0.00 & 8494.79 & 0.00 \\
0.25 & 8762.50 & 3.15 \\
0.30 & 8773.13 & 3.28 \\
0.35 & 9168.75 & 7.93 \\
0.40 & 11718.00 & 37.94 \\
0.45 & 9810.42 & 15.49 \\
0.50 & 9392.97 & 10.57 \\
\hline
\end{tabular}

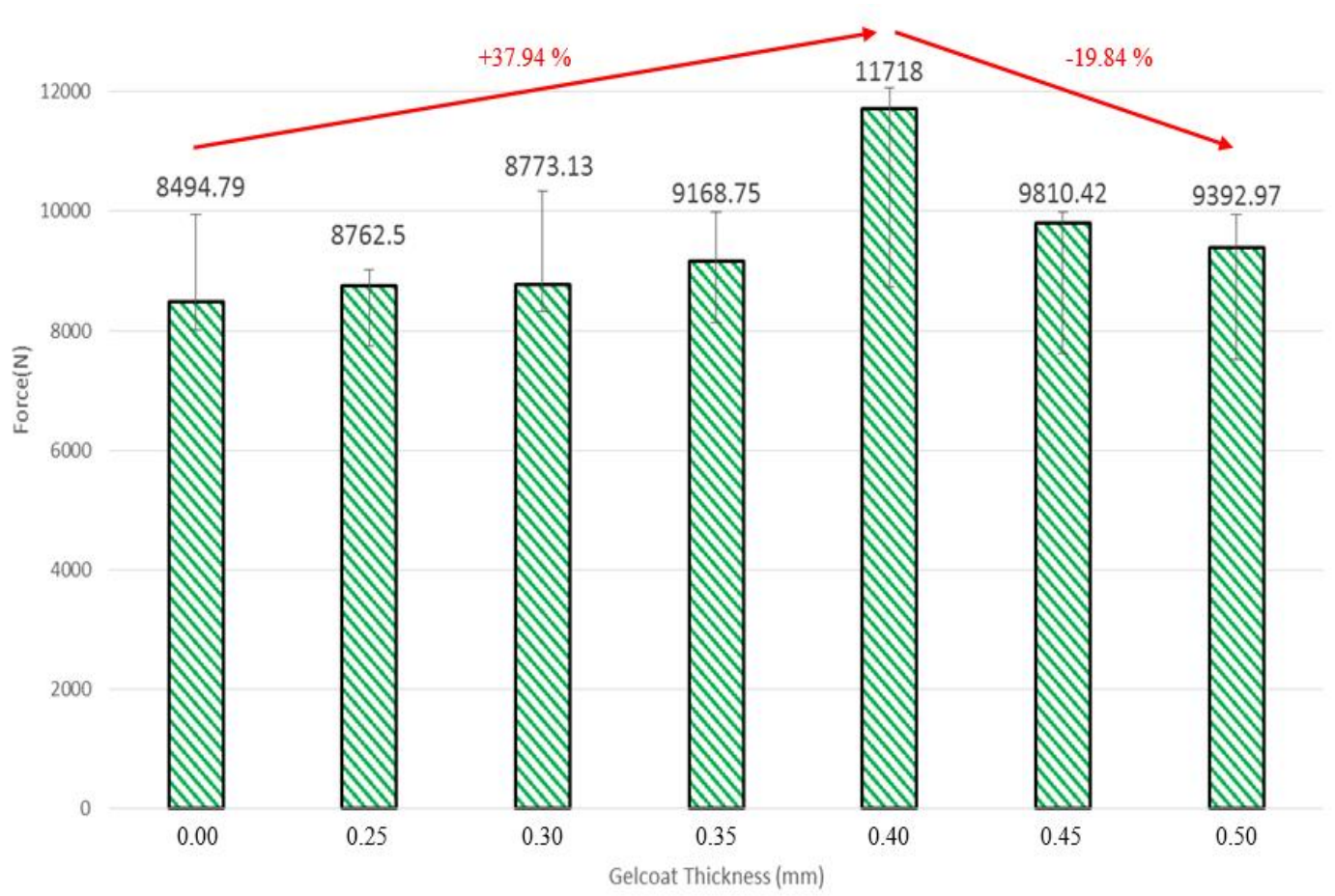

Figure 12. Graph of average maximum force sustained by glass/polyester composite coated with gelcoat of different thickness. 


\section{CONCLUSIONS}

The present study was designed to determine the effects of gelcoat thickness on the flexural and tensile properties of glass/polyester laminated composite are investigated as an approach to estimate the optimum gelcoat thickness for the composite. This study has shown that the composites coated with $0.30 \mathrm{~mm}$ thick gelcoat give the highest flexural strength for both measurement methods, i.e., gelcoat facing up and gelcoat facing down. The gelcoat thickness of $0.40 \mathrm{~mm}$ is found to give the highest tensile strength, in which an increase of almost $38 \%$ compared to the uncoated composite. It was also shown that the most obvious failure is the brittle fracture of the gelcoat layer. The higher the gelcoat thickness, the brittleness of gelcoat becomes. There are clear and clean crack edges that can be seen where the failure occurs. The delamination of matrix occurs within the four plies. From the observation on SEM, the interface of gelcoat and laminate composite are strongly bonded in each gelcoat thickness and most final failures are caused by the delamination. The only poor interface bonding is done by the void appear at the interface zone. The crack propagates through the void that eventually lowers the mechanical strength. The finding of this study suggest that the optimum gelcoat thickness for glass/polyester laminated composite is in the range of 0.30 and $0.40 \mathrm{~mm}$ to yield the best mechanical properties. Further research in this field/regarding the role of gelcoat thickness would be of great help in composite industry.

\section{ACKNOWLEDGEMENT}

The authors thankful to Skim Zamalah UTeM for financial support. Part of this research is supported under the Fundamental Research Grant Scheme provided by the Ministry of Higher Education Malaysia No. FRGS/1/2017/TK03/FTK-AMC/F00343.

\section{REFERENCES}

[1] Yuhazri MY, Sihombing H, ZA MZ, Nilson GCH. A review on gelcoat used in laminated composite structure.International Journal of Research in Engineering and Technology. 2015;4:49-58.

[2] See SC and Zhang ZY. Richardson MOW. A study of water absorption characteristics of a novel nano-gelcoat for marine application. Progress in Organic Coatings. 2009;65:169-174.

[3] Karapappas P, Tsotra P and Scobbie K. Effect of nanofillers on the properties of a state of the art epoxy gelcoat. eXPRESS Polymer Letters. 2011;5:218-227.

[4] Sockalingam S, Nilakantan G. Fiber-matrix interface characterization through the microbond test. International Journal of Aeronautical \& Space Science 2012;13:282-295.

[5] Lacovara B. Get wise to gel coat cracks: characterizing crack defects. Convergent Composites, American Composites Manufacturers Association. 2010;1-8.

[6] Mouritz AP, Gibson AG. Fire properties of polymer composite materials. Springer Science \& Business Media. 2007;143:279-280.

[7] Pomázi Á, Toldy A. Particle distribution of solid flame retardants in infusion moulded composites. Polymers. 2017; 9:250. 
[8] Capela C, Ferreira JM, Cravo H, Costa JM. Fatigue and impact response of gelcoated glass mats/ polyester composites. Journal of Composite Materials. 2013; 48:1131-1137.

[9] McCrary-Dennis MCL, Okoli OI. A review of multiscale composite manufacturing and challenges. Journal of Reinforced Plastics and Composites. 2012;31:1687-1711.

[10] CCP Composites Australia Corp. Gelcoat Troubleshooters Guide. CCP Composites Application Guide. 2014.

[11] Ennos AR, Casteren AV. Transverse stresses and modes of failure in tree branches and other beams. The Royal Society B. 2010; 277:1253-1258.

[12] Li Q, Zhao JC, Zhao B. Fatigue life prediction of a rubber mount based on test of material properties and finite element analysis. Engineering Failure Analysis. 2009;16:2304-2310.

[13] Knoeller SL, Rome NY. Polymer matrix composite manufacturing induced defects. Advanced Materials, Manufacturing and Testing. 2009;5:7-10.

[14] Baghaei B, Skrifvars M, Berglin L. Manufacture and characterisation of thermoplastic composites made from PLA/hemp co-wrapped hybrid yarn prepregs. Composites Part A: Applied Science and Manufacturing. 2013;50:93101.

[15] Orifici A. Control of composite material crack branching for improved fracture toughness, $29^{\text {th }}$ Congress of the International Council of the Aeronautical Science. Germany, 7 - 12 September 2014. 2014:1-8.

[16] Maksimović S. Postbuckling and failure analysis of axially compressed composite panels using FEM. Scientific Technical Review. 2007;57:.43-48.

[17] Khelifa MZ, Al-Shukri HM. Fatigue study of e-glass fiber reinforced polyester composite under fully reversed loading and spectrum loading. Eng Technol. 2008;26:1210-1224.

[18] Kalia S, Dufresne A, Cherian BM, Kaith BS, Avérous L, Njuguna J, Nassiopoulos E. Cellulose-based bio- and nanocomposites - a review. International Journal of Polymer Science. 2011:1-35.

[19] Jawahar P, Kanny K, Balasubramanian M. Influence of nanoclay addition on properties of unsaturated-polyester nanocomposite gel coat system. Journal of Polymer Engineering. 2009;29:563-580.

[20] Scott Bader Company Limited. Crystic Polyester Handbook, Wollaston, Wellingborough, Northamptonshire. 2005.

[21] Muralidharan B, Summerscales J. Resin infusion under flexible moulding technique by in-mould gel coating using a flow medium. Indian Journal of Applied Research. 2013;3:292-293.

[22] Clegg S, Haugaard M. The SAGE Handbook of Power, SAGE Publication. 2009.

[23] Adams D. Composites on Yachts: Rigged for success, CW Composites World. 2010.

[24] Krstulović-Opara L, Garafulić E, Klarin B, Domazet Ž. Application of gradient based IR thermography to the GRP structures inspection. Key Engineering Materials. 2012;488-489:682-685.

[25] Ahmad S, Izhar UH. Wind Blade Material Optimization. Applied Mechanics \& Materials. 2011;66-68:1199-1206. 
[26] Kumara MS, Raghavendraa K, Venkataswamya MA, Ramachandrab HV. Fractographic analysis of tensile failures of aerospace grade composites, Materials Research. 2012;15:990-997.

[27] Chaturvedi MC. Welding and Joining of Aerospace Materials, Woodhead Publishing Limited. 2012:98. 